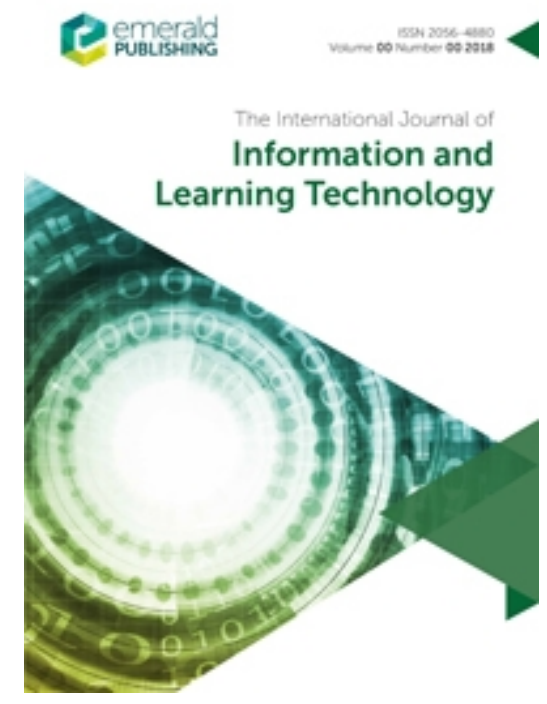

\title{
Facilitating Factors in Cultivating Diverse Online Communities of Practice: A Case of International Teaching Assistants during the COVID-19 Crisis
}

\begin{tabular}{|r|l|}
\hline Journal: & International Journal of Information and Learning Technology \\
\hline Manuscript ID & IJILT-05-2020-0074.R2 \\
\hline Manuscript Type: & Case Study \\
\hline Keywords: & $\begin{array}{l}\text { Communities of Practice, diversity, international teaching assistants, } \\
\text { COVID, online }\end{array}$ \\
\hline \multicolumn{2}{|l}{} \\
\hline
\end{tabular}

\section{SCHOLARONE ${ }^{\text {M }}$ Manuscripts}




\title{
Facilitating Factors in Cultivating Diverse Online Communities of Practice:
}

\author{
A Case of International Teaching Assistants during the COVID-19 Crisis
}

\author{
By $X X X X X X$ \\ March 2020 \\ $X X X X X X X X X X$ University
}




\begin{abstract}
Purpose: This study aims to identify facilitating factors in cultivating a linguistically and culturally diverse virtual Community of Practice and techniques in tailoring such support for international graduate teaching assistants (ITAs) at a US university while assessing indications for ITAs' selfperceptions in four key areas: social connectedness, confidence teaching in English, pedagogical support, and self-efficacy in teaching.

Design/Methodology: This mixed-methods case study qualitatively analyzes open-ended responses utilizing a Grounded Action Research approach along with follow-up interviews of ITAs. Quantitative measures of key perception areas between three "Experience Groups" were conducted to identify potential correlations with involvement in the CoP.

Findings: Calculations using the Kruskal-Wallis test of differences yielded no statistically significant results. However, qualitative analyses highlight ITAs' needs, classified into four general concepts and 16 specific core categories. Evaluation of CoP communications suggest COVID-19 and a sudden transition to online teaching represented recognizable shared problems that invigorated the CoP and overshadowed diversity-related factors.

Implications: These findings have implications for culturally and linguistically diverse CoPs and particularly for ITA training programs worldwide, allowing universities to enhance support of ITAs and bolster development of undergraduate programs especially during times of crisis and transitions to online learning.

Originality: The first study to investigate an international, multilingual ITA population in a virtual CoP regardless of academic discipline, this contributes by addressing several common CoP criticisms, including cultivation in distributed contexts and in further guiding expectations for its adoption into culturally and linguistically diverse communities.

Classification: Case study

Keywords: Communities of Practice, diversity, online, virtual, multilingual, multicultural, international teaching assistants
\end{abstract}




\section{Introduction}

This case study investigates facilitating factors in cultivating a virtual Community of Practice (VCoP) that is both linguistically and culturally diverse, and its role, if any, in benefiting international teachings assistants (ITAs) at a university on the northeast coast of the United States (UNCU), particularly as ongoing social, linguistic, and pedagogical support. Despite their growing presence in US institutions, ITAs are perceived negatively compared to their Americanborn counterparts (Li at al., 2011; Gorsuch, 2016; Manohar and Appiah, 2015) and experience overwhelming amounts of distress in their transition into US campus life (Smith and Khawaja, 2011; Sherry et al., 2010). Aiming to alleviate their concerns, given the social and sharingfocused nature of CoPs (Wenger at al., 2002), the cultivation of a VCoP could serve as added support for first-year ITAs at UNCU. Still, a major criticism of this framework lies within its extension to broader cultural contexts (Ardichvili et al., 2006; Jewson, 2013; Hildreth et al., 2000; Roberts, 2006; Kerno, 2008; Passerini et al., 2020; Malinen, 2015); this study addresses this issue by integrating culturally and linguistically diverse individuals into a fully-online VCoP due to the emergence of COVID-19. Considering globalization trends across universities and workplaces, such diversity in CoPs is becoming less of an anomaly and more a norm. This study sheds light on the following research questions and sub-question:

1. Which factors facilitate the cultivation of an energetic virtual CoP with linguistically and culturally diverse membership?

2. How can such CoPs be designed to benefit ITAs specifically?

a. Do such benefits include heightened self-perceptions of confidence teaching in English, pedagogical support, self-efficacy in teaching, or social connectedness on campus among first-year ITAs?

\section{Literature Review}

ITAs in the United States

Graduate teaching assistants are graduate students who teach lower-level undergraduate courses in exchange for stipends and/or tuition. This is financially beneficial to both students and universities (Krislov, 2019). Okahana and Zhou (2018) state that approximately $24 \%$ of graduate students in the US in 2017 were internationals, many of whom fulfill TA roles. This number differs by academic department: up to $80 \%$ of graduate students in STEM departments at several US universities in 2017 were internationals (Jain, 2019). Clearly, ITAs comprise a considerable presence at American universities.

Unfortunately, various studies outline American undergraduates' negative attitudes toward ITAs. They are often viewed as having linguistic inadequacies (Li et al., 2011; Gorsuch, 2016) and receive lower student evaluations compared to American TAs (Manohar and Appiah, 2015). Work by Meyer and Mao (2015) demonstrates that American students also perceive ITAs as creating classroom environments that are less desirable than those developed by American TAs.

Still, how to best support ITAs remains uncertain, as exemplified by extensive disparities between ITA training programs across the US. They differ in content, duration, and timing of training 
administration: some programs last one weekend; others run concurrently to ITAs' first full semester teaching. Most take place during their first summer on campus, sometimes a full year before they begin teaching (Hou et al., 2018) and before internationals have acquired awareness of their own pedagogical weaknesses and/or needs in such early stages (Hou, 2014).

Furthermore, negotiating social circles is of major concern to ITAs (Smith and Khawaja, 2011), $56 \%$ of whom report experiences of isolation, loneliness, and discrimination at American campuses (Sherry et al., 2010). Acknowledging that TAs report feeling that they receive insufficient supervision, guidance, and feedback in their workload (Wise, 2011), combined with the need for earlier self-identification of weaknesses (Hou, 2014), social learning over time in CoPs may, logically, serve as effective for ITAs socially, linguistically, and pedagogically.

Notably, though numerous studies have documented success with CoPs with career instructors (Caldwell and Heaton, 2016), findings may not extend to TAs, especially for those who do not intend to teach as a career (Parker, 2014).

\section{Communities of Practice in diverse and distributed contexts}

The concept of Communities of Practice (CoP) was first introduced by Lave and Wenger (1991), providing groundwork for situated learning and the notion of workplace learning as outcomes of social interaction. Theories on identities of novice versus expert practitioners are presented, along with the learning processes involved throughout paths of professional growth within larger organizations as social settings. Learning in a CoP, then, being social in nature, may enhance ITAs' sense of connectedness while requiring them to negotiate teaching-centered topics in English, thus providing social, linguistic, and instructional support. Wenger (1998) takes CoPs further in highlighting the paths of individuals' trajectories across levels of participation as they move toward more central roles and in addressing conflict between individuals within these levels, a noted criticism of Wenger's earlier conceptualizations (Li et al., 2009). This sort of "conflict" goes against the grain in many cultures, as demonstrated in literature involving international graduate students which suggest that individuals of certain cultural backgrounds may become timid or passive in their interactions with those in positions above theirs (Hou, 2015) or "experts," as defined by Wenger. This corroborates other findings on culture's influence in knowledge-sharing and communication preferences, including power negotiations, competitiveness, modesty in public settings, and collectivist ideologies (Passerini et al., 2020; Ardichvili et al., 2006; Hildreth et al., 2000; Kerno, 2008), which may interact unpredictably in widely diverse CoPs. As such issues of diversity are addressed, albeit limitedly, in Wenger et al. (2002), and for its shift toward emphasis on cultivating CoPs, this iteration of the framework most informed the approaches adopted in the development of this study's CoP, particularly its seven principles for traversing a CoP's stages of maturity.

Here, Wenger et al. (2002) do address global communities as one subset of distributed communities - or communities that are unable to connect physically (p.115) - and briefly outline issues that commonly arise from within them; yet, the recommendations discussed are minimal and optimistic. In cultivating CoPs under distributed-albeit not specifically globalcircumstances, they provide a series of vague recommendations such as "achieving stakeholder

http://mc.manuscriptcentral.com/cwis 
alignment," "building a rhythm," and "developing the private space of the community more systematically" without details of what stakeholder alignment is beyond shared interests, average amounts of timing or rhythms, or how to gauge private interactions, respectively. Perhaps the most effective strategy presented involves inclusion of both "local variations" and "global connections" (pp.124-130). Although COVID-19 immediately halted this study's community's ability to gather, many distributed CoPs cannot develop a "local variation" at all under any circumstances, making this so-called solution optimistic. Noticeably minimal, also, are implications regarding members' comfort in using a given technological platform or tool and the training and/or access needed, especially when international members are involved (Khalid et al., 2014).

Wenger et al. (2002) admit their proposed remedies are more suited for larger CoPs and that intercultural and linguistic matters add further nuance. They suggest little in designing to overcome diversity-related challenges. That socio-cultural factors may impede on the cultivation of active CoPs remains among the primary criticisms of CoP frameworks (Ardichvili et al., 2006; Hildreth et al., 2000; Roberts, 2006; Kerno, 2008). Kerno (2008) provides a compilation of major downfalls of CoPs, highlighting "regional culture" as one of the three most pervasive shortcomings of the framework. He corroborates the cultural findings addressed above in discussing the impact of culture on one's communication inclinations and styles and notes also the severe shortage of cross-cultural research on CoPs. Ardichvili et al. (2006), perhaps most extensively to date, outlines culture's role in VCoPs, addressing the impact of cultural influences such as collectivism, competitiveness, modesty, and communication styles in knowledge seeking and sharing. Still, the study is limited to four nationalities and one academic specialty (engineering) while also having a large number of members representing each nationality-two stark differences compared to the study at hand.

\section{Applying an extended framework}

Among the few studies that have reviewed impacts of CoPs with diverse membership are a dissertation with international healthcare students, in which participants learn communication techniques with in-person practice sessions (Guinea, 2016); a blended face-to-face and distributed approach by Hildreth et al. (2000); and a group of English language learners whose CoP interactions were both a course requirement and practiced during class (Khalsa, 2012). Authors of each study assert the importance of in-person components in their CoPs' success, limiting the extendibility of their findings to non-distributed CoPs, but required CoP interaction as a coursework grade, thus violating a key element of the framework: voluntary participation. Per Wenger et al. (2002), CoP membership is self-selected and voluntary, and can be classified by level of participation, which should grow in frequency, intensity, and trust in later stages.

However, this study differs from those undertaken above not only in its purely voluntary membership, but also in its multilingual/multicultural factors and its online environment, which may likely affect this VCoP's active participation. In reviews of activity in VCoPs, numerous studies address members' motivations for contributing, often including incentives, elements of competition, or consequences to elicit activity (Passerini et al., 2020; Curtis, 2018; Tan and Ramayah, 2018), none of which are present here either. Nonetheless, Wenger et al. (2002) states 
that participants should not be expected to contribute equally; it should not be assumed that they are not learning silently, peripherally, given that "people have different levels of interest in the community" (p. 55).

Presently, a CoP by definition involves primarily a shared domain, engagement within the community, and shared practical resources, as published previously but maintained on his current website (Wenger-Trayner and Wenger-Trayner, 2015). Though many tenets of the framework have been modified over time, noticeably absent remain updated discussions on the evolving web-based nature of communication and the diversity of global communities. Thus, the study at hand presents a case that involves a relatively small sample size but a uniquely rich CoP membership in cultural and linguistic diversity that must operate strictly online; in other words, it involves a combination of factors that are increasingly common but minimally explored or resolved by Wenger et al. (2002) or other research to date.

\section{The Case at UNCU}

UNCU runs two ITA training sessions per year: four-week courses before Fall and two-week courses before Spring. Training course-loads consist of two to four of the following:

- Pronunciation of American English: provides explicit speaking practice

- Oral Intelligibility: aims to improve intonation through drama

- Culture and Pedagogy: reviews basic teaching skills in American university settings

- University Workshop: features presentations from representatives on legal topics and campus resources

All ITAs are required to enroll in Culture and Pedagogy and University Workshop. Enrollment in language courses depends on departmental requirements and ITAs' speaking abilities as assessed on-site by UNCU's English language department. ITAs who do not reach departmental requirements cannot teach discussion sections or labs and must enroll in upcoming ITA training sessions while fulfilling non-teaching duties in the meantime, such as grading or tutoring.

\section{Predictions}

Based on previous findings of commonly identified hardships among ITAs (CITE), content geared toward the areas of pedagogical, social, and linguistic support would serve as shared problems and interests that would invigorate the CoP. Discussions from Wenger et al. (2002) suggested that the VCoP, being fully online and diverse in culture and language by nature, would move more slowly through the stages of cultivation compared to more homogeneous or in-person CoPs, though a timeline for such movement has not been outlined in the literature to date. Furthermore, it was expected that first-year ITAs who engage in the VCoP would perceive themselves as feeling more confident in their English for instructional purposes, more socially connected, more pedagogically supported, and more effective in their role as instructors compared to first-year ITAs who did not join the CoP. First-years who did not join the CoP were expected to feel less linguistically confident, socially connected, pedagogically supported, and effective compared to both the experienced ITAs and the first-years who did join the CoP. In 
these same four areas, the CoP group and the Experienced group were expected to respond statistically similarly, though the Experienced group, with their informed knowledge of teaching at UNCU, may be found to perceive themselves more positively than the CoP group.

\section{Methods and Methodology}

This case study utilizes a mixed-methods design involving analysis of open-ended responses, quantitative measurement of surveyed perceptions, and evaluation of contributions to the CoP. All participants granted informed consent across all domains of the study and were contacted via active UNCU email addresses with links to surveys.

\section{Participants - Initial Survey with Open-Ended Questions}

Because of the mixed design of this study, different components of the research involved distinct sets of participants. Data from the initial survey, described in detail in the Instruments section below, was collected at the start of the semester from 79 ITAs (table I) at UNCU, representing 27 nationalities. All UNCU ITAs who participated in ITA training between 2014 and 2020 with active UNCU email addresses were sent the link to participate in the initial survey. As PhD programs at UNCU typically last at least five years, with many extending beyond this timeline, even ITAs from the 2014 cohort were likely still fulfilling ITA duties at the time of the study or had graduated within the year.

\section{Table I: Initial Survey Participants: Open-Ended Data; Table II: Post-Survey Participants}

\section{Participants-Post-Survey}

Data on ITAs' perceptions in the four key areas were collected from a post-survey that was sent seven weeks after the initiation of the CoP. 52 ITAs (table II) responded to the post-survey and represented a total of 20 nationalities. Of these 52 respondents, eight were CoPs members who span five nationalities.

\section{Survey Instrument}

The initial survey consisted of 24 questions: 9 demographic, 8 perceptual, and 7 open-ended. Open-ended questions were informed by work from Austin (2002) on ITAs' attitudes toward campus support resources. The items measuring perceptions in the four key areas consisted of adapted items from questionnaires (table III) that have been previously tested for reliability; this reliability may be affected as abbreviated versions of each were included to comprise this particular instrument.

\section{Table III: Reliability of Adapted Instruments}

These eight items were 10-point Likert-type, ranging from Strongly disagree to Strongly agree, or Nothing to A great deal for items adapted from the TSES.

Procedure of Surveys

All ITAs were first sent a SurveyMonkey link to the initial survey via email one week before the semester. CoP members were asked to also complete a post-survey consisting of five 
demographics and the same eight perceptual questions as the initial survey after their experience in the CoP in order to allow for greater amounts of time, interaction, and potential effect with the CoP. However, given the unexpected yet extensive changes to ITAs' instructional duties and overall involvement at UNCU resulting from COVID-19, all groups of participants were asked to complete the post-survey to allow for fairer comparison on the perception questions across all three groups. Therefore, all quantitative data derive from the post-survey responses of 52 participants whereas the open-ended data derive from the initial survey's 79 respondents.

Procedure: Cultivating the VCOP

Invitations were sent to first-year ITAs to join a Facebook group aimed at providing support and a secure space for questions regarding teaching, campus life, or US culture. Participation was selfselected and voluntary. 18 ITAs (table IV) joined. The other four members consisted of me (an ITA instructor and the CoP's core member/coordinator), another ITA program instructor, a previous ITA training program administrative assistant, and an experienced second-year UNCU ITA.

Table IV: Members of CoP

Facebook was selected for its flexibility with global communities and its facilitation of easilyaccessible public and private communications, and the demonstrated positive effects on members' sense of "social connectedness" when social networking components are present in e-CoPs (Hung and Yuen, 2010). Additional research has shown that ITAs report feeling inhibited in expressing uncertainty or requesting help in the presence of professors or academic advisers (Cowan, 2012), even online (Kenney et al., 2013), while Austin (2002) demonstrates the value of informal communications in shaping TAs' instructional habits and illustrates that ITAs prefer to direct their questions in informal settings. In light of these findings, non-ITA members of academic departments were not invited to participate in the VCoP.

\section{Results}

Data obtained from open-ended questions in the initial survey were analyzed using a Grounded Action Research method, outlined by Strauss and Corbin (1990) and replicated by Baskerville and Pries-Heje (1999), to identify key themes. Data from the post-survey were analyzed using the Kruskal-Wallis test of differences for non-parametric ordinal data at a significance level of .05 (Cohen et al., 2011).

\section{Findings of Open-Ended Responses}

To classify themes that emerged from the open-ended survey responses on to questions related to their ITA duties, a Grounded Action Research approach was utilized to provide rich insight into lived experiences of ITAs. This method combines Action Research, as participants were working with me, the researcher, to implement positive change to their own organizational structures at UNCU (Reason and Bradbury-Huang, 2007), along with Grounded Theory in that the volume of open-ended responses was somewhat unexpected; no hypothesis regarding their direction was made at the start of data collection. 
To identify core categories, participants' responses were first-coded to distinguish key concepts. From there, axial coding assisted in the development of relationships between concepts to form categories. Theory then emerges to form core categories that shape narratives for interpretation. From this point, the action research cycle may begin again.

To exemplify, one core category that emerged was the teaching of unfamiliar content. Statements such as "My course topics aren't related to my educational background," "The courses I'm assigned to TA don't relate to my research or field," and "I'm from a different scientific background but was given a challenging engineering course to TA" were first placed, among other data, into the concept of "workload," then to the category of "content-related workload stress," and finally to the core category of "lack of familiarity or interest in TA course content." In total, 16 core categories emerged from four general concepts. All core categories have several distinct pieces of ITA feedback attributed to them, with numerous ITAs often corroborating the same notions and the ideas of more departmental-specific information and educational technology being repeated across several core categories.

Core categories with the most variety in responses, along with a number of examples statements from ITAs, include:

- $\quad$ Disagreement between ITA and Professor on Grading Matters

- "My prof graded leniently, and I didn't expect this, though I see now that it keeps the students motivated."

- The professor didn't take grading seriously and it was really demoralizing for me as the TA; I started to care less."

- "Some supervisors don't care if their students cheat, copy homework, how homework is gradedthat made me more reluctant to do the job."

- Planning for the Sudden Transition to Online Instruction

- "Need more suggestions about TA activities for online courses."

"Everything takes longer to teach online."

- "I had to spend so much time moving everything to an online format and making new homework questions when we went online."

- "Is there somewhere on campus we can go to borrow or fix tech equipment?"

- "More practice with using teaching websites."

- $\quad$ A Need for Differentiated Training

- "Each department is very unique and it is very possible that TAs have to readjust to their requirements after ITA training."

- "More focused training sessions are needed. For example, make a special class for TAs in the area of math and natural sciences."

- "It would help if departments or even TAs saved their lessons or worksheets together or shared online activities; it would be easier for TAs coming from a different background to teach in different departments. For example, from mathematics to mechanical engineering."

- Student Issues

- "Classroom management techniques should be more deeply addressed." 


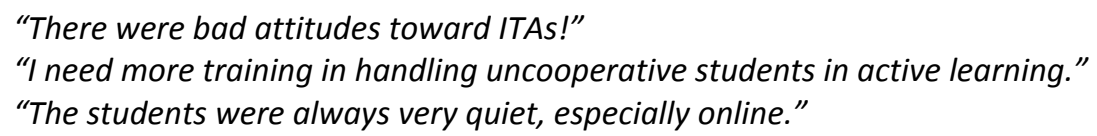

All core categories can be found in table $\mathrm{V}$ below. Any responses that did not fit into any of the general concepts and were not corroborated by another ITA were excluded.

Table V: Lists of Concepts, Categories, and Core Categories

Findings in CoP Cultivation

The data were extracted seven weeks into the cultivation of the CoP although only four of these weeks coincided with UNCU's teaching schedule, unexpectedly. The CoP began one week before the semester in order to help ITAs with first-week preparations. After just two weeks of teaching, however, UNCU was forced to push forward its spring break week and add an additional, unanticipated break week to evacuate its campus in light of COVID-19.

The CoP consisted of 22 total members representing 13 nationalities. Given the percentage breakdowns projected by Wenger et al. (2002, p.56), we expect 2-3 core members, 4-5 active members, and 14-16 peripheral members, though for the purposes of this study, active members represent individuals who interacted (table VI) in the CoP in any capacity. I myself am the coordinator and only core member.

Table VI: CoP Contributions of Core and Active Members

Early posts contained content intended to provide social, linguistic, and pedagogical support of ITAs, such as UNCU graduate student event announcements, articles on the unique characteristics of US undergraduate campus experience including both cultural and linguistic information, and inviting stories, questions, or concerns regarding their first week of teaching, respectively. However, after three weeks into the CoP, only three ITAs and two non-ITA members had contributed. Acknowledging the findings of cross-cultural, multilingual CoPs in which explicit instruction was provided to members (Ehrenreich, 2010; Guinea, 2016; Khalsa, 2012), I sent a brief email encouraging ITAs to contribute, along with reminders of appropriate topics and responses. Within hours of this correspondence, the emergence of COVID-19 in the area, specifically on UNCU's campus, was announced. Soon after, CoP activity increased, marking firstcontributions from numerous members. However, it is worth noting that fourteen of the fifteen posts-numbers which do not include the strings of comments and reactions within each initial post-during the four weeks of heightened activity included information about teaching online and/or COVID, and all but two generated ITA interaction within the reactions and comments sections, at times building on each other's previous responses. Over the seven weeks total, active ITA members engaged in 62 interactions, 59 of which occurred during the latter four weeks of the CoP.

It is crucial to note that these interactions were always in response to initial posts made by the VCoP coordinator. Aside from three ITAs who contacted me in private spheres, ITAs had not yet begun initiating posts or engaging, at least in public spaces of the CoP, with each other. 
This lack of independent interaction may be the result of the cultural issues found by Ardichvili et al. (2006), but may also be a consequence of lacking a face-to-face foundation from which to build trust (Guinea, 2016; Hildreth et al., 2000; Khalsa, 2012), an insufficient amount of time to build rapport with one another (Wenger et al., 2002), as well as ITAs' widely varied academic backgrounds and, therefore, diverse perceived needs. Furthermore, it is quite possible that ITAs had not yet had opportunities to face or identify their areas of weakness, which is typical for firstyear ITAs (Hou, 2014); crucial periods of the semester including exams, grading, homework, etc. had not yet occurred.

Peripheral members were categorized based on their sustained presence in the CoP: these individuals (table VII) did not interact in its public space but continued to visit the Facebook page throughout all seven weeks.

Table VII: CoP Peripheral Members and Early Leavers

The majority of these members read 18-23 of the 23 posts; all read at least 12 . Early Leavers never contributed or stopped viewing posts after the initial two weeks or earlier.

Semi-structured follow-up Facebook private chat interviews with four ITA members representing four different nationalities and languages, selected for their relatively high levels of engagement in the CoP, were conducted upon completion of the UNCU spring semester. The purpose of these interviews was to gather data regarding their experience as an ITA during COVID, their activity in the CoP, and their perceptions of its usefulness.

All interviewed ITAs stated that they experienced heightened levels of stress in response to their ITA duties as a result of COVID-related changes at UNCU. An ITA from Bangladesh acknowledged that transition often brings added stress that that it is "even more so with COVID-19." One ITA from Pakistan recounted that he spent considerable time on "making online labs for students to perform at home" while an ITA from Korea explained that her "professor and TAs decided to make a question bank so Canvas can pick random questions for each student so nobody gets the same set of questions." She also added that she "had to respond to more emails from students because they were panicking in general about everything." When asked about why they never initiated a post, one of the four stated that he does not use Facebook much while the other three discussed "shyness," "never taking initiative in group settings," "or "not feeling comfortable sharing... with others I barely know," though they acknowledged that these feelings were mitigated when they had the opportunity to respond to a post by the facilitator; giving answers was less intimidating or personal to them. Two also explicitly mentioned that they likely would have felt more of an inclination to "collaborate" if other ITAs from their department had been involved in the community. Still, though they only ever responded when prompted, three of the four interviewed ITAs believe that they benefited from the CoP. An ITA from India noted that she "felt more confidence teaching online" as a result; another felt more socially connected at a time when everyone "felt distant". Another added "As an inexperienced TA, some help in teaching is still required after the training period is over. This provided me that additional support." 
Findings of the Post-Survey

Participants were categorized into three "Experience Groups." Respondents in the First-Year category participated in UNCU's ITA training program during Summer 2019 or Winter 2020. The Experienced group consists of ITAs who underwent training at some point between Summer 2014 and Winter 2019, inclusive. The CoP group represents post-survey responses from ITAs who joined the CoP.

Crucially, sample sizes of all survey response groups were small; results can be regarded as indicative only. Data were analyzed using the Kruskal-Wallis measure of differences for nonparametric ordinal data at a significance level of .05 (Cohen et al., 2011). No statistically significant differences were found between the experience groups for any of the four key areas of perception (table VIII).

Table VIII: Findings of Kruskal-Wallis Tests

Acknowledging the lack of statistical significance, ITAs' perceptions of having pedagogical support on campus show the greatest promise for future work ( $\chi 2=4.544, \rho=0.103)$. Also, slight differences in mean ranks (table IX), though not statistically significant, are present and in favor of the CoP group across all perception areas, possibly indicating promise for future work.

Table IX: Mean Ranks of Four Perception Areas by Experience Group

Furthermore, as shown in Table VIII, perception of pedagogical support was the closest p-value $(p=.103)$ to statistical significance. However, when reviewing mean ranks, the greatest differences appear to be between the CoP and Experienced groups, which was not expected.

Table $\mathrm{X}$ below shows descriptive statistics of the sample for a clearer view of means, which are the highest across the CoP groups in each perception area, though crucially not statistically significant.

\section{Table X: Descriptive Statistics of Perceptions}

With standard deviations reaching as high as 3.03, where responses range on average across more than half of the 10-point scale, ITAs are showing great variation in their perceptions. Increased numbers of participants and questions in each category is needed to yield more generalizable data.

\section{Discussion}

Wenger et al. (2002) state that, by definition, a CoP is a group of people "who share a concern, a set of problems, or a passion about a topic, and who deepen their knowledge and expertise in this area by interacting on an ongoing basis." He also admits outright that dispersed, or in this case virtual, CoPs, as well as either culturally or linguistically diverse CoPs, are expected to require more time in the early development stages of Potential, Coalescing, and Maturing without giving 
clear timelines or expectations for their cultivation. This particular study combined all three characteristics in an effort to assess whether such a diverse CoP, though having shared problems, concerns, and passions about a topic, could be of relevance to a group as heterogeneous as firstyear ITAs. That ITAs at UNCU want sustained support throughout their first year of teaching is clear: a resounding 64 of 79 (81\%) of them indicated this in the open-ended survey when asked.

In responding to the first research question, there is clear evidence that a shared problem is among the factors that facilitate the cultivation of a diverse VCoP. However, identifying what constituted a "shared" problem was not readily transparent, especially not to a group of strangers from different backgrounds and academic disciplines and especially during the first few weeks of the CoP. This is discussed in interviews with ITAs who stated that they felt shy or uncomfortable to post their plans, actions, or concerns online to share with individuals whom they did not yet know, which also may signify that a considerable amount of time or effort may be needed in the Coalescing stage to develop trust, another facilitating factor. Evidence for a shared problem that is apparent to all in the community is further demonstrated by the lack of activity or interaction among ITAs in spite of repeated attempts on the part of the facilitator to invigorate the community with a variety of content in early posts. However, following the sudden closure of the campus and the imminent transition to online classes, a shared problem was easily identifiable as relevant to all. Following, the CoP became comparatively active, with ITAs disclosing their lesson topics in search of online materials and sharing ideas on how to move forward with cases of cheating online, for example. While it is true that the posts were initiated by the facilitator, reactions and comments to initial posts became markedly more abundant. Still, this lack of initiation should not be taken as a lack of social learning per se with culturally diverse CoPs (Ardichvili et al., 2006; Malinen, 2015; Passerini et al., 2020), given that differences in cultural influences on communication and of collectivism, competitiveness, saving face, and hierarchy impact one's approach in sharing and seeking knowledge.. Furthermore, Wenger et al. (2002) state that members at all levels of participation should be accepted as learners and CoP members-a crucial difference compared to previous iterations of the framework. Follow-up interviews with ITAs did indeed reveal that social learning was occurring and that ITAs perceived themselves as having benefited from the interactions, though a desire for more homogeneity in their academic backgrounds and teaching duties was expressed both in follow-up interviews as well as the open-ended survey response; the 18 ITA-CoP members represent 12 different academic departments. Inclusion of more members from each department, or, in generalizing to a wider range of diverse VCoPs, a shared academic or professional background or experience, may likely help to invigorate an otherwise heterogenous community more quickly.

Guidance or encouragement may also be taken as a facilitating factor in cultivating a culturally and linguistically diverse VCoP. Not only is this in line with literature on developing CoPs with classes of mixed-background non-native English speakers (Guinea, 2016; Hildreth et al., 2000; Khalsa, 2012) but also aligns with the sudden uptick in interaction in the Facebook CoP observed here: upon sending a brief email to ITAs with possible CoP topics and examples of acceptable responses to posts, ITAs did engage with the facilitator's posts. In the follow-up interview, one ITA noted that she felt she better understood the purpose of the CoP after receiving this email and began interacting, in part, as a result of it. This "guidance" may also help ITAs to feel less 
vulnerable in communicating individual challenges or needs: when examples are elicited by a facilitator, ITAs may feel that their struggles appear less as a personal weakness. ITAs shared stories, ideas, and advice, but never sought advice in the CoP, which contradicts findings from the open-ended survey data which clearly outlines a number of areas of support needs across all experience levels.

In cultivating an VCoP specifically for a diverse community of ITAs, in addition to the facilitating factors discussed above, the open-ended survey data becomes crucial in needs identification, which may likely reflect relevance and therefore perceived value of a potential CoP and may in part be pertinent to training, departmental, and campus-wide factors specific to UNCU. Still, prior research on ITAs (Smith and Khawaja, 2011; Sherry et al., 2010; Austin, 2002) illustrate sufficient common ground to be able to extend at least a sizeable number of findings to other programs. Based on the open-ended survey data, general concepts that emerged with respect to ITAs' needs consist primarily of concerns related to workload, department- or campus-level support, diversity, and student behaviors and motivations. The 16 core categories (see table V) illustrate a number of more specific needs that, when presented in a CoP setting, may elicit more interaction, given that they provide information regarding ITAs' widely shared problems, which, as outlined above, appear to be a facilitating factor in energizing new, diverse VCoPs. ITAs explicitly state, along with a demand for technology-based practice given the presence and likely continuance of COVID-19, that these core categories require additional training, with a request for discipline-specific policy transparency, observations, shareable materials, lesson ideas, and overall departmental collaboration at the heart of many comments made across the 16 core categories. However, this does not necessarily signify that ITA VCoPs should be restricted to the departmental level, as "crossover" from one discipline into an only tangentially-related one was frequently discussed by ITAs as a significant problem in their TA experience, and also in that the CoP was discussed in follow-up interviews as socially beneficial in connecting to ITAs outside of their own department. Including experienced ITAs into the VCoP would have increased the likelihood of overlap between academic departments and further extended social connections, perhaps further invigorating the VCoP.

It is important to note that many of these core categories discussed largely by more experienced ITAs may not naturally have come to light in the first-year CoP due to a lack of opportunity to occur: because of COVID-19, the semester was delayed and little grading had occurred at the time of data collection; student behavioral issues may have been less of an issue in online classes; language-related issues may have been mitigated due to online presentation of pre-made materials and less dependence on traditional lecturing on a chalkboard; and access to campus resources was shut down entirely. Based on follow-up interviews, the most overwhelming stressor of the semester was the sudden increase in material development-a topic that was in fact discussed by ITAs in the VCoP.

These unexpected changes to UNCU's semester due to COVID-19 likely played a significant role in the responses of the post-survey data. Nonetheless, in answering the research sub-question regarding ITAs' self-perceptions in areas commonly identified as being of concern in previous 
literature (Li et al., 2011; Gorsuch, 2016; Smith and Khawaja, 2011; Sherry et al., 2010), a preliminary statistical review yields interesting findings to be used for indicative purposes only.

Perceptions of one's confidence teaching in English is the highest reported mean across all Experience groups. This initially seems to conflict with open-ended survey data, in which language and cultural issues emerge as core categories of concern for ITAs. A deeper look into the data shows that $52 \%$ of the 27 respondents who reported having language-related concerns come from China, Iran, or Taiwan, which is relatively high, given that 27 nationalities were represented in the open-ended survey. However, there were no active VCoP members from China, Iran, or Taiwan, nor did any Chinese or Iranian ITAs complete the post-survey from the VCoP group, including peripheral members, which may account for the seeming disparity.

Data from post-survey perceptions, though not statistically significant and purely indicative, show the greatest disparity in mean ranks between the CoP group and the Experienced group, which could reflect that first-year ITAs may not yet be able to predict the degree of support they will need, in line with findings from Hou (2014), whereas the Experienced group may have sought support in the past and faced difficulties obtaining it.

\section{Limitations}

Unfortunately, the sample size of ITAs was limited with only one university involved, making all findings purely indicative. With more participants and additional qualitative data, perhaps in the form of a longitudinal study, results may become more reflective of the ITA experience in the US. Segmenting data by department, language background, or other factors may also account for wide variations in ITA perceptions and needs.

A limitation of the open-ended initial survey was the exclusion of CoP-specific questions. The intention was to avoid cuing responses on perception questions. However, as CoP cultivation progressed, an earlier emergence of ITAs' opinions on ongoing needs could have energized the community. In retrospect, the open-ended survey data or similar needs analysis should have been conducted before the launch of the VCoP.

Similar CoPs will likely see more success by including in-person components. Members' inability to meet during the pandemic may have inhibited independent communication between each other. Offers to set up "Zoom" meetings were unsuccessful, perhaps due to the CoP's infancy or stressful conditions resulting from COVID in general, such as evacuations of campus, dormitories, labs, and the sudden need to develop a wide variety of lessons, materials, and assessments.

\section{Future Research}

Further studies on this topic may benefit from inclusion of experienced ITAs in the CoP. This may increase interactions and social aspects of the group while improving its perceived value, assuming others from similar disciplines are involved. CoP impact may also be greater if trust and rapport are initially built in face-to-face environments, or more time is allotted to the VCoP cultivation and data gathering. Assessing benefits of shaping CoPs around departmental, cultural, or linguistic needs may also create interesting areas of research. 
Additional research may also benefit from the adoption of qualitative designs that provide comprehensive views of the lived experiences of ITAs. Conducting interviews throughout a yearlong CoP, for example, may generate data that inspires improvement in ITA training programs. Deeper investigations into CoP interactions may highlight specific types of posts that most energize ITA-CoP members. In a systematic review of the literature on VCoPs, Malinen (2015) states an overabundance of research regarding the sheer quantity of participants' communications versus content exploration, often resulting in a misleading overrepresentation only the most active members' CoP experiences. Comparing similar data from universities, especially with longer or shorter ITA training programs, could provide insight into the enhancement of training and support programs.

\section{Conclusion}

ITAs comprise sizeable proportions of TAs in the US. These individuals face significant academic, cultural, social, and linguistic pressure in overwhelming new environments. The situated learning involved in CoPs was projected to help ITAs in their feelings of social connectedness and adaption to their new, multi-faceted roles at the university. The goal of this mixed-methods case study was to provide additional evidence outlining expectations of culturally and linguistically diverse CoPs in a fully distributed, online setting, to identify any facilitating factors that may serve to encourage interaction in a highly heterogenous community, to illustrate how such a support system may benefit ITAs specifically, and to assess participants' perceptions of their confidence teaching in English, social connectedness, pedagogical support, and instructional self-efficacy based on experience and CoP participation. Results from this study show that there is no statistical significance in the four perception areas, though combining these data with findings from the CoP, open-ended questions, and follow-up interviews demonstrate the need for support for ITAs across four general concepts of ITA workload, departmental- and campus-wide needs, diversity, and student-related issues. Access to discipline-specific resources and knowledge of educational technologies spans across a number of core categories of ITA perceived needs and is becoming increasingly essential, notably in the time of COVID-19. 


\section{References}

Ardichvili, A., Maurer, M., Li, W., Wentling, T. and Stuedemann, R. (2006), "Cultural influences on knowledge sharing through online communities of practice", Journal of Knowledge Management, Vol. 10 No. 1, pp.94-107. 10.1108/13673270610650139

Austin, A.E. (2002), "Preparing the next generation of faculty: graduate school as socialization to the academic center", The Journal of Higher Education, Vol. 73 No. 1, pp.94-122.

10.1080/00221546.2002.11777132

Baskerville, R. and Pries-Heje, J. (1999), "Grounded action research: a method for understanding IT in practice", Accounting, Management and Information Technologies, Vol. 9 No. 1, pp.1-23. 10.1016/S0959-8022(98)00017-4

Caldwell, H. and Heaton, R. (2016), "The interdisciplinary use of blogs and online communities in teacher education", The International Journal of Information and Learning Technology, Vol. 33 No. 3, pp.142-158. 10.1108/IJILT-01-2016-0006

Chacón, C.T. (2005), “Teachers' perceived efficacy among English as a foreign language teachers in middle schools in Venezuela", Teaching and Teacher Education, Vol. 21 No. 3, pp.257-272. 10.1016/j.tate.2005.01.001

Cohen, L., Manion, L. and Morrison, K. (2011), Research Methods in Education, 7th ed., Routledge, London.

Cowan, J. (2012), "Strategies for developing a community of practice: nine years of lessons learned in a hybrid technology education master's program", TechTrends, Vol. 56 No. 1, pp.1218. 10.1007/s11528-011-0549-x

Curtis, V. (2018), "Participant interaction: from online forums to virtual communities of practice", In: Online Citizen Science and the Widening of Academia. Palgrave Macmillan, London, pp. 143-165. 10.1007/978-3-319-77664-4_7

Ehrenreich, S. (2010), "English as a business lingua franca in a German multinational corporation: meeting the challenge", International Journal of Business Communication, Vol. 47 No. 4, pp.408-431. 10.1177/0021943610377303

Eisenberger, R., Huntington, R., Hutchison, S. and Sowa, D. (1986), "Perceived organizational support", Journal of Applied Psychology, Vol. 71 No. 3, pp.500-507. 10.1037/00219010.71.3.500

Gorsuch, G. (2016), "International teaching assistants at universities: a research agenda", Language Teaching, Vol. 49 No. 2, pp.275-290. 10.1017/S0261444815000452 
Guinea, S.E. (2016), "Employing communities of practice to facilitate international culturally and linguistically diverse nursing students' identities as learners in Australia through immersive simulation", PhD, Monash University.

Hildreth, P., Kimble, C. and Wright, P. (2000), "Communities of practice in the distributed international environment", Journal of Knowledge Management, Vol. 4 No. 1, pp.27-38. $10.1108 / 13673270010315920$

Hou, H. (2015), "What makes an online community of practice work? A situated study of Chinese student teachers' perceptions on online professional learning", Teacher and Teacher Education, Vol. 46, pp.6-16. 10.1016/j.tate.2014.10.005

Hou, N. (2014), "Testing the Effect of Timing of Delivery of a Cross-Cultural Training Program", MS, Auburn University.

Hou, N., Fan, J., Tan, J.A., Hua, J. and Valdez, G. (2018), "Cross-cultural training effectiveness: does when the training is delivered matter?", International Journal of Intercultural Relations, Vol. 65 No. 1, pp.17-29. 10.1016/j.ijintrel.2018.03.007

Hung, H. and Yuen, S.C. (2010), "Educational use of social networking technology in higher education", Teaching in Higher Education, Vol. 15 No. 6, pp.703-714.

10.1080/13562517.2010.507307

Jain, V. (2019), "U.S. graduate students in STEM are mostly foreign", The Washington Post, 26 September, available at: https://www.washingtonpost.com/opinions/us-graduate-students-instem-are-mostly-foreign/2019/09/25/65b28098-de37-11e9-be7f-

4cc85017c36f_story.html\#comments-wrapper (accessed 22 November 2019).

Jewson, N. (2013), "Cultivating network analysis: Rethinking the concept of "community" within "communities of practice", Hughes, J., Jewson, N., and Unwin, L. (Ed.s), Communities of Practice: Critical Perspectives, Routledge, London.

Kenney, J., Kumar, S. and Hart, M. (2013), “More than a social network: Facebook as a catalyst for an online educational community of practice", International Journal of Social Media and Interactive Learning Environments, Vol. 1 No. 4, pp.355-369. 10.1504/IJSMILE.2013.057467

Kerno, S.J., Jr. (2008), "Limitations of communities of practice" a consideration of unresolved issues", Journal of Leadership \& Organizational Studies, Vol. 15 No. 1, pp.69-78.

$10.1177 / 1548051808317998$

Khalid, F., Joyes, G., Ellison, L., and Daud, M.Y. (2014), “Factors influencing teachers' level of participation in online communities", International Education Studies, Vol. 7 No. 13, pp.23-30. 10.5539/ies.v7n13p23 
Khalsa, D.K. (2012), "Creating communities of practice: active collaboration between students", England, L. (Ed.), Online Language Teacher Education: TESOL Perspectives, Routledge, New York, pp.81-92. 10.4324/9780203813263

Krislov, M. (2019), "Why international students are good for colleges, universities and America", Forbes, 22 March, available at:

https://www.forbes.com/sites/marvinkrislov/2019/03/22/why-international-students-aregood-for-colleges-universities-and-america/\#b5a244ef496f (accessed 19 November 2019).

Lave, J. and Wenger, E. (1991), Situated Learning: Legitimate Peripheral Participation. Cambridge University Press, Cambridge, U.K.

Lee, R.M. and Robbins, S.B. (1995), "Measuring belongingness: the Social Connectedness and Social Assurance Scales", Journal of Counseling Psychology, Vol. 42 No. 2, pp.232-241. 10.1037/0022-0167.42.2.232

Li, L., Mazer, J.P. and Ju, R. (2011), "Resolving international teaching assistant language inadequacy through dialogue: challenges for opportunities for clarity and credibility", Community Education, Vol. 60 No. 4, pp.461-478. 10.1080/03634523.2011.565352

Li, L.C., Grimshaw, J.M., Nielsen, C., Judd, M., Coyte, P.C., and Graham, I.D. (2009), "Evolution of Wenger's concept of community of practice", Implementation Science, Vol. 4, No. 11. https://doi.org/10.1186/1748-5908-4-11

Malinen, S. (2015), "Understanding user participation in online communities: a systematic literature review of empirical studies", Computers in Human Behavior, Vol. 46, pp.228-238. 10.1016/j.chb.2015.01.004

Manohar, U. and Appiah, O. (2015), "Perspective taking to improve attitudes towards international teaching assistants: the role of national identification and prior attitudes", Communication Education, Vol. 65 No. 2, pp.149-163. 10.1080/03634523.2015.1081956

Meyer, K.R. and Mao, Y. (2015), "Comparing student perceptions of the classroom climate created by U.S. American and international teaching assistants", Higher Learning Research Communications, Vol. 4 No. 3, pp.12-22. 10.18870/hlrc.v4i3.206

Okahana, H. and Zhou, E. (2018), International Graduate Applications and Enrollment: Fall 2017, Council of Graduate Schools, Washington, DC, available at: https://cgsnet.org/ckfinder/userfiles/files/Intl_Survey_Report_Fall2017.pdf (accessed 20 November 2019). 
Parker, P. (2014), "An Examination of the Impact of Pedagogical Preparation, Teaching Experience and Future Career Plans on Mathematics Graduate Teaching Assistants' Efficacy", $\mathrm{PhD}$, Georgia State University.

Passerini, K., Osatuyi, B., and Stipe, W. (2020), "Giving and taking in online communities of practice: the role of geography and culture in knowledge sharing and innovation", The 53 Hawaii International Conference on System Sciences, University of Hawaii, 7-10 January.

Reason, P. and Bradbury-Huang, H. (2007), The SAGE Handbook of Action Research: Participative Inquiry and Practice, SAGE Publications Ltd, London.

Roberts, J. (2006), "Limits to communities of practice", Journal of Management Studies, Vol. 43 No. 3, pp.623-639. 10.1111/j.1467-6486.2006.00618.x

Smith, R.A. and Khawaja, N.G. (2011), "A review of the acculturation experiences of international students", International Journal of Intercultural Relations, Vol. 35 No. 6, pp.699713. 10.1016/j.ijintrel.2011.08.004

Sherry, M., Thomas, P. and Chui, W.H. (2010), "International students: a vulnerable student population”, Higher Education, Vol. 60 No. 1, pp.33-46. 10.1007/s10734-009-9284-z

Strauss, A. and Corbin, J. (1990), Basics of Qualitative Research: Grounded Theory Procedures and Techniques, Sage, Newbury Park, CA.

Tan, C.N. and Ramayah, T. (2018), "Exploring the individual, social, and organizational predictors of knowledge-sharing behaviours among communities of practice of SMEs in Malaysia", Journal of Systems and Information Technology, Vol. 20 No. 3, pp. 375-399. 10.1108/JSIT-09-2017-0071

Tschannen-Moran, M. and Woolfolk Hoy, A. (2001), "Teacher efficacy: capturing and elusive construct", Teaching and Teacher Education, Vol. 17, pp.783-805. 10.1016/S0742051X(01)00036-1

Wenger, E. (1998), Communities of Practice: Learning, Meaning, and Identity, Cambridge University Press, Cambridge, U.K.

Wenger, E., McDermott, R. and Snyder, W. M. (2002), Cultivating Communities of Practice: A Guide to Managing Knowledge, Harvard Business School Press, Boston, MA.

Wenger-Trayner, E. and Wenger-Trayner, B. (2015), "Introduction to communities of practice: a brief overview of the concept and its uses", available at: https://wengertrayner.com/introduction-to-communities-of-practice/ (accessed 30 November 2020)

Wise, A. (2011), "Supporting future faculty in developing their teaching practices: an exploration 
of communication networks among graduate teacher assistants", International Journal of Teaching and Learning in Higher Education, Vol. 23 No. 2, pp.135-149. 
Table I: Initial Survey Participants: Open-Ended Data

\begin{tabular}{|c|c|}
\hline $\begin{array}{c}\text { Region of Origin and } \\
\text { Nations Represented }\end{array}$ & $\begin{array}{c}\text { Number of Survey } \\
\text { Participants }\end{array}$ \\
\hline $\begin{array}{c}\text { Africa } \\
\text { Ghana, Nigeria, Uganda }\end{array}$ & 5 \\
\hline $\begin{array}{c}\text { Americas } \\
\text { Colombia, United States (Attended school in Japan) }\end{array}$ & 3 \\
\hline $\begin{array}{c}\text { East Asia } \\
\text { China, Japan, Korea, Taiwan, Vietnam }\end{array}$ & 19 \\
\hline $\begin{array}{c}\text { Europe } \\
\text { Belgium, Bulgaria, France, Germany, Greece, Italy, } \\
\text { Russia, Spain }\end{array}$ & 12 \\
\hline $\begin{array}{c}\text { Middle East/North Africa } \\
\text { Iran, Israel-Palestine, Lebanon, Turkey }\end{array}$ & 10 \\
\hline $\begin{array}{c}\text { South Asia } \\
\text { Bangladesh, India, Nepal, Pakistan, Sri Lanka }\end{array}$ & 28 \\
\hline $\begin{array}{c}\text { Unreported Nationality } \\
\text { Total Number of Participants }\end{array}$ & 2 \\
\hline$\quad$
\end{tabular}

Table II: Post-Survey Participants

\begin{tabular}{|c|c|c|c|c|}
\hline Region of Origin and Nations Represented & $\begin{array}{l}\text { First-Year, } \\
\text { Non-CoP }\end{array}$ & Experienced & $\begin{array}{l}\text { First-Year, } \\
\text { CoP }\end{array}$ & Regional Totals \\
\hline $\begin{array}{c}\text { Americas } \\
\text { Colombia, United States (Attended school in } \\
\text { Japan), Venezuela }\end{array}$ & 2 & - & - & 2 \\
\hline $\begin{array}{c}\text { Africa } \\
\text { Ghana, Nigeria, Uganda }\end{array}$ & 3 & 1 & - & 4 \\
\hline $\begin{array}{c}\text { East Asia } \\
\text { China, Korea, Taiwan }\end{array}$ & 5 & 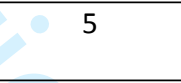 & 1 & 11 \\
\hline $\begin{array}{c}\text { Europe } \\
\text { Greece, Italy, Russia }\end{array}$ & - & 7 & - & 7 \\
\hline $\begin{array}{c}\text { Middle East /North Africa } \\
\text { Egypt, Iran, Turkey }\end{array}$ & 3 & 3 & - & 6 \\
\hline $\begin{array}{c}\text { South Asia } \\
\text { Bangladesh, India, Nepal, Pakistan, Sri Lanka }\end{array}$ & 10 & 5 & 7 & 22 \\
\hline Total Number of Nations Represented $=20$ & & & & $\begin{array}{c}\text { Total } \\
\text { Participants }=52\end{array}$ \\
\hline
\end{tabular}

Table III: Reliability of Adapted Instruments

\begin{tabular}{|c|c|c|}
\hline Area of Perception & Instrument & $\begin{array}{c}\text { Cronbach's } \\
\text { Alpha Coefficient }\end{array}$ \\
\hline Social Connectedness & $\begin{array}{c}\text { Social Connectedness Scale } \\
\text { (Lee and Robbins, 1995) }\end{array}$ & Not applicable \\
\hline Confidence Teaching in English & $\begin{array}{c}\text { English Teachers' Sense of Efficacy Scale } \\
\text { (Chacón, 2005) }\end{array}$ & $\begin{array}{c}\text { Teachers' Self-Reported } \\
\text { Proficiency }\end{array}$ \\
\hline Pedagogical Support & $\begin{array}{c}\text { Survey of Perceived Organizational Support } \\
\text { (Eisenberger et al., 1986) }\end{array}$ & $\begin{array}{c}\text { Not applicable } \\
\text { Self-Efficacy in Teaching }\end{array}$ \\
\hline $\begin{array}{c}\text { Teachers' Sense of Efficacy Scale } \\
\text { (Tschannen-Moran and Woolfolk Hoy, } \\
\text { 2001) }\end{array}$ & $\begin{array}{c}\text { Student Engagement; } \\
\text { Instructional Strategies }\end{array}$ \\
\hline
\end{tabular}


Table IV: Members of CoP (Excluding coordinator)

\begin{tabular}{c|c|c|c|c}
\hline $\begin{array}{c}\text { Region and Nationalities } \\
\text { Americas } \\
\text { United States }\end{array}$ & Active & Peripheral & $\begin{array}{c}\text { Early } \\
\text { Leavers }\end{array}$ & $\begin{array}{c}\text { Regional } \\
\text { Totals }\end{array}$ \\
\hline $\begin{array}{c}\text { Africa } \\
\text { Uganda }\end{array}$ & $\mathbf{2}$ & $\mathbf{1}$ & - & $\mathbf{2}$ \\
\hline $\begin{array}{c}\text { East Asia } \\
\text { China, Korea, Myanmar }\end{array}$ & $\mathbf{2}$ & $\mathbf{3}$ & $\mathbf{1}$ & $\mathbf{6}$ \\
\hline $\begin{array}{c}\text { Europe } \\
\text { Malta, Ukraine }\end{array}$ & - & - & $\mathbf{2}$ & $\mathbf{2}$ \\
\hline $\begin{array}{c}\text { Middle East /North Africa } \\
\text { Iran, Turkey }\end{array}$ & $\mathbf{1}$ & $\mathbf{1}$ & - & $\mathbf{2}$ \\
\hline $\begin{array}{c}\text { South Asia } \\
\text { Bangladesh, India, Nepal, Pakistan }\end{array}$ & $\mathbf{5}$ & $\mathbf{3}$ & - & $\mathbf{8}$ \\
\hline Totals Nations = 13 & $\mathbf{1 1}$ & $\mathbf{8}$ & $\mathbf{3}$ & $\mathbf{2 2}$ \\
\hline
\end{tabular}

Table V: Lists of Concepts, Categories, and Core Categories

\begin{tabular}{|c|c|c|c|c|c|}
\hline \multirow[t]{2}{*}{$\begin{array}{l}\text { Concept 1: } \\
\text { Workload }\end{array}$} & Categories & Content-Related & Grading & Lesson-Planning & $\begin{array}{c}\text { Time } \\
\text { Management }\end{array}$ \\
\hline & $\begin{array}{c}\text { Core } \\
\text { Categories }\end{array}$ & $\begin{array}{l}\text { Lack of } \\
\text { Familiarity or } \\
\text { Interest in TA } \\
\text { Course Content }\end{array}$ & $\begin{array}{c}\text { Disagreement between } \\
\text { ITA and Professor on } \\
\text { Grading } \\
\text { Individual Challenges } \\
\text { with Grading }\end{array}$ & $\begin{array}{l}\text { Planning Content } \\
\text { and Activities } \\
\text { Planning for the } \\
\text { Sudden Transition } \\
\text { to Online } \\
\text { Instruction } \\
\text { Timing and Pacing } \\
\text { of a Lesson }\end{array}$ & $\begin{array}{c}\text { Managing Large } \\
\text { Classes }\end{array}$ \\
\hline \multirow[t]{2}{*}{$\begin{array}{c}\text { Concept 2: } \\
\text { Support } \\
\text { Needs }\end{array}$} & Categories & \multicolumn{2}{|c|}{ Departmental-Level } & & \\
\hline & $\begin{array}{c}\text { Core } \\
\text { Categories }\end{array}$ & \multicolumn{2}{|c|}{ A Need for Differentiated Training } & \multicolumn{2}{|c|}{ Lack of Information or Training } \\
\hline \multirow{2}{*}{$\begin{array}{c}\text { Concept 3: } \\
\text { Student } \\
\text { Issues }\end{array}$} & Categories & \multicolumn{2}{|c|}{ Classroom Management } & \multicolumn{2}{|c|}{ Academically } \\
\hline & $\begin{array}{c}\text { Core } \\
\text { Categories }\end{array}$ & \multicolumn{2}{|c|}{ Behavior Issues } & \multicolumn{2}{|c|}{ A Lack of Prior Knowledge in Course Content } \\
\hline
\end{tabular}




\begin{tabular}{|cc|c|c|}
\hline $\begin{array}{c}\text { Concept 4: } \\
\text { Diversity }\end{array}$ & Categories & Culture & Language \\
\cline { 2 - 4 } & $\begin{array}{c}\text { Core } \\
\text { Categories }\end{array}$ & Understanding and Relatability & $\begin{array}{c}\text { "No specific core category; } \\
\text { ITAs simply noted "language barriers" }\end{array}$ \\
& & On Behalf of Students & \\
\hline
\end{tabular}

Table VI: CoP Contributions of Core and Active Members

\begin{tabular}{|c|c|c|c|c|c|c|}
\hline Level of Participation & $\begin{array}{c}\text { \# of } \\
\text { Likes }\end{array}$ & $\begin{array}{c}\text { \# of } \\
\text { Comments }\end{array}$ & $\begin{array}{c}\text { \# of } \\
\text { Posts }\end{array}$ & $\begin{array}{c}\text { Private } \\
\text { Correspondence }\end{array}$ & $\begin{array}{c}\text { Total } \\
\text { Contributions } \\
\end{array}$ & Nationality \\
\hline \multirow[t]{2}{*}{ Core (Coordinator) } & 2 & 27 & 23 & 9 & 61 & USA \\
\hline & & & & & & 1 member \\
\hline Active & 5 & 2 & 2 & 4 & 13 & USA \\
\hline \multirow[t]{6}{*}{ Americas Totals } & 5 & 2 & 2 & 4 & 13 & 1 \\
\hline & 2 & 1 & 0 & 0 & 3 & India \\
\hline & 0 & 0 & 0 & 2 & 2 & India \\
\hline & 2 & 1 & 0 & 2 & 5 & India \\
\hline & 10 & 6 & 0 & 0 & 16 & Bangladesh \\
\hline & 1 & 1 & 0 & 0 & 2 & Nepal \\
\hline \multirow[t]{3}{*}{ South Asia Totals } & 15 & 9 & 0 & 4 & 28 & 5 \\
\hline & 4 & 7 & 0 & 0 & 11 & Korea \\
\hline & 0 & 1 & 0 & 0 & 1 & Myanmar \\
\hline \multirow[t]{2}{*}{ East Asia Totals } & 4 & 8 & 0 & 0 & 12 & 2 \\
\hline & 0 & 0 & 0 & 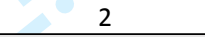 & 2 & Turkey \\
\hline \multirow[t]{2}{*}{ Middle East Totals } & 0 & 0 & 0 & 2 & 2 & 1 \\
\hline & 3 & 2 & 0 & 2 & 7 & Uganda \\
\hline Africa Totals & 3 & 2 & 0 & 2 & 7 & 1 \\
\hline $\begin{array}{c}\text { CoP Active Member } \\
\text { Totals }\end{array}$ & 27 & 21 & 2 & 12 & 62 & 10 members \\
\hline
\end{tabular}

Table VII: CoP Peripheral Members and Early Leavers

\begin{tabular}{|c|c|c|c|}
\hline \multicolumn{2}{|r|}{ Peripheral } & \multicolumn{2}{|c|}{ Early Leavers } \\
\hline Gender & Nationality & Gender & Nationality \\
\hline \multirow{2}{*}{1} & Iran & 1 & China \\
\hline & Middle East $=1$ & & East Asia $=1$ \\
\hline 2 & China & 1 & Ukraine \\
\hline \multirow[t]{2}{*}{1} & Korea & 1 & Malta \\
\hline & East Asia $=3$ & & Europe $=2$ \\
\hline 2 & India & & 3 Early leavers \\
\hline \multirow[t]{2}{*}{1} & Pakistan & & \\
\hline & South Asia = 3 & & \\
\hline \multirow[t]{3}{*}{1} & USA & & \\
\hline & Americas $=1$ & & \\
\hline & 8 Periperhal members & & \\
\hline
\end{tabular}

Table VIII: Findings of Kruskal-Wallis Tests

\begin{tabular}{rrrr}
$\begin{array}{c}\text { Confidence } \\
\text { in English }\end{array}$ & $\begin{array}{c}\text { Pedagogical } \\
\text { Support }\end{array}$ & $\begin{array}{c}\text { Self-Efficacy } \\
\text { in Teaching }\end{array}$ & \multicolumn{2}{c}{$\begin{array}{c}\text { Social } \\
\text { Connectedness }\end{array}$} \\
\hline 1.430 & 4.544 & 1.818 & 1.408
\end{tabular}

Kruskal-Wallis $\mathrm{H}$ 4.544 1.818 


\begin{tabular}{lrrrr}
\hline df & 2 & 2 & 2 & 2 \\
\hline Asymp. Sig. & .489 & .103 & .403 & .495 \\
\hline
\end{tabular}

Table IX: Mean Ranks of Four Perception Areas by Experience Group

\begin{tabular}{lr|r|r|r|r}
$\begin{array}{l}\text { Experience } \\
\text { Group }\end{array}$ & N & $\begin{array}{c}\text { Confidence } \\
\text { in English }\end{array}$ & $\begin{array}{c}\text { Pedagogical } \\
\text { Support }\end{array}$ & $\begin{array}{c}\text { Self-Efficacy } \\
\text { in Teaching }\end{array}$ & \multicolumn{2}{c}{$\begin{array}{c}\text { Social } \\
\text { Connectedness }\end{array}$} \\
\hline First Year & 23 & 24.00 & 29.39 & 24.11 & 28.20 \\
\hline Experienced & 21 & 27.60 & 21.24 & 26.88 & 23.52 \\
\hline CoP & 8 & 30.81 & 32.00 & 32.38 & 29.44 \\
\hline Total & 52 & & & & \\
\hline
\end{tabular}

Table X: Descriptive Statistics of Perceptions

Confidence in English Pedagogical Support Self-Efficacy in Teaching Social Connectedness

\begin{tabular}{c|c|c|c|c|c|c|c|c|c}
\hline Group & $n$ & $M$ & $S D$ & $M$ & $S D$ & $M$ & $S D$ & $M$ & $S D$ \\
\hline First Year & 23 & 8.22 & 1.9 & 8.14 & 1.95 & 7.15 & 1.73 & 7.13 & 2.62 \\
\hline Experienced & 21 & 8.71 & 1.52 & 7.45 & 2.3 & 7.36 & 1.79 & 6.57 & 3.03 \\
\hline CoP & 8 & 9.06 & 1.06 & 8.94 & 1.81 & 8.19 & 1.22 & 7.38 & 2.3 \\
\hline
\end{tabular}

